\title{
Enhancing Mechanical Properties of Mg-6Zn Alloy by Deformation-Induced Nanoprecipitation
}

\author{
Kai Yan ${ }^{1} \cdot$ Huan Liu ${ }^{2} \cdot$ Xiaowei Xue $^{3} \cdot$ Jing Bai ${ }^{4} \cdot$ Honghui Chen ${ }^{1}$. Shuangquan Fang ${ }^{1} \cdot$ Jingjing Liu $^{1}$
}

Received: 23 June 2020 / Revised: 20 July 2020 / Accepted: 25 July 2020 / Published online: 12 October 2020

(c) The Chinese Society for Metals (CSM) and Springer-Verlag GmbH Germany, part of Springer Nature 2020

\begin{abstract}
We presented the solution of deformation-induced precipitation after homogenization to enhance the mechanical properties of $\mathrm{Mg}-6 \mathrm{Zn}$ alloys. The results show that the improved strategy exhibits more effective strengthening role than grain refinement methods based on low-temperature severe plastic deformation under the same strain. The low-temperature deformation with larger extrusion ratio results in massive nano-sized precipitates and excellent mechanical properties with the yield strength of $355 \mathrm{MPa}$ and the ultimate tensile strength of $405 \mathrm{MPa}$. The increased mechanical properties are strong and tough enough to resist the stress and not be worn away when the alloy nail penetrates through the pig thigh bone, potentially extending more orthopedic surgery applications for $\mathrm{Mg}-\mathrm{Zn}$ alloys.
\end{abstract}

Keywords Mg-6Zn alloy $\cdot$ Equal channel angular pressing $\cdot$ Deformation-induced precipitation $\cdot$ Severe plastic deformation $\cdot$ Mechanical property

\section{Introduction}

Extensive interest in degradable metal for implants has led to numerous notable literature and important progress in this field, especially the $\mathrm{Mg}-\mathrm{Zn}$ binary alloys have attracted great attention as a biodegradable material due to their good biocompatibility and good biosafety [1-5]. With respect to the applications of biodegradable implants, mechanical and corrosion properties of a material are the most important [6]. As a proper biocompatible element, $\mathrm{Zn}$ could improve corrosion resistance of $\mathrm{Mg}$ alloys by elevating the corrosion

Available online at https://link.springer.com/journal/40195.

Kai Yan

yankai@yzu.edu.cn

$\triangle$ Huan Liu

liuhuanseu@hhu.edu.cn

1 College of Mechanical Engineering, Yangzhou University, Yangzhou 225127, China

2 College of Mechanics and Materials, Hohai University, Nanjing 211100, China

3 Northern Jiangsu People's Hospital Affiliated to Yangzhou University, Yangzhou 225001, China

4 School of Materials Science and Engineering, Southeast University, Nanjing 211189, China potential, promoting the intact corrosion film and elevating the charge transfer resistance of magnesium [7-9]. Taking into account $\mathrm{Zn}$ concentrations over solubility limit (approximately $6.2 \mathrm{wt} \%$ in $\mathrm{Mg}-\mathrm{Zn}$ binary alloy), corrosion properties are deteriorated due to the formation of secondary phases and the consequent galvanic couple effect, which are responsible for production of excessive hydrogen gas [10-13]. In addition, the mechanical properties of $\mathrm{Mg}-\mathrm{Zn}$ alloys with the $\mathrm{Zn}$ concentration ranging from 1.0 to $6.0 \mathrm{wt} \%$ increased with $\mathrm{Zn}$ content $[6,7,14]$. Therefore, on the whole, $\mathrm{Mg}$ $6 \mathrm{Zn}$ alloy shows advantages over its potential rivals in the application of biomedical implants.

In the last two decades, an enormous amount of research effort had gone into ultrafine-grained $\mathrm{Mg}$ alloys. Especially, the severe plastic deformation (SPD) technologies were introduced to refine microstructure, imposing large deformation to $\mathrm{Mg}$ alloys at temperature as low as possible and reducing the grain size to the micron and even submicron scale [15-18]. However, these technologies only can improve the ultimate tensile strength of $\mathrm{Mg}-\mathrm{Zn}$ series alloys to at most $370 \mathrm{MPa}$ [19-27]. Recently, some exceptional high strengths, such as about $390 \mathrm{MPa}$ in yield strength (YS) and $440 \mathrm{MPa}$ in ultimate tensile strength (UTS), have been achieved in deformation processed ZK60 Mg alloys [28, 29]. These materials are characterized by larger grain sizes of about $7 \mu \mathrm{m}$, and their high strengths are attributed to the 
nano-scaled precipitates, the formation of substructures and the modification of non-basal texture. The common point to the emerging technologies is that the low-temperature deformation at the last procedure induces the nanoprecipitation as a thermal-mechanical aging treatment. Before that all the alloys have been fully homogenized to improve precipitation effect. From this, it indicates that we might employ a new strategy based on the deformation-induced precipitation followed by fully homogenization to develop the ultra-high strength $\mathrm{Mg}-6 \mathrm{Zn}$ alloy.

Since the metal bars are the necessary materials for orthopedic devices such as Kirschner wire and tapping bone nail, in this study, we integrated the forming process and designed a comparative experiment to investigate its influence on microstructures and mechanical properties of $\mathrm{Mg}-6 \mathrm{Zn}$ alloy based on the two strengthening strategies, i.e., fine grain strengthening and deformation-induced precipitation strengthening. Moreover, the mechanism of deformationinduced precipitation strengthening for $\mathrm{Mg}-6 \mathrm{Zn}$ alloy was discussed.

\section{Experimental}

The experimental materials used for this investigation were the $\phi 15$-mm-extrusion rod (sample EX) with a nominal composition of $6 \mathrm{wt} \% \mathrm{Zn}$ and $\mathrm{Mg}$ balance. The samples were processed by six passes of equal channel angular pressing (ECAP) with inner angle of $90^{\circ}$ and route $\mathrm{B}_{\mathrm{C}}$ at a pressing speed of $1.5 \mathrm{~mm} / \mathrm{s}$ and then were die extruded to thin rods for use in Kirschner wire. The temperature of extrusion should be as low as possible to ensure the high mechanical properties of the resulting rods. The $\mathrm{Mg}-6 \mathrm{Zn}$ rods were processed by two processing routes. The route A represents the strengthening strategy toward microstructure refinement, the samples were ECAP processed at the lower temperature of $160{ }^{\circ} \mathrm{C}$ for 6 passes (sample A1) and then extruded into $\phi 2.6 \mathrm{~mm}$ rods at $180{ }^{\circ} \mathrm{C}$ with the extrusion ratio of about 33 (sample A2). The route B represents the strategy toward deformation-induced precipitation followed by complete homogenization. The samples were ECAP processed at a higher temperature of $320^{\circ} \mathrm{C}$ for 6 passes (sample B1) and then extruded into $\phi 2.6 \mathrm{~mm}$ rods at $180{ }^{\circ} \mathrm{C}$ with the extrusion ratio of about 33 (sample B2). Thus, it can be seen that the two routes have nearly identical processes except the temperatures of ECAP processing (Table 1).

Microstructural observations were conducted by an optical microscope (OM, Leica DMI3000M), a field-emission scanning electron microscope (SEM, Hitachi S-4800II) and a transmission electron microscope (TEM, Tecnai G2). The OM and SEM samples were cut along transverse cross section, grinded with a series of $\mathrm{SiC}$ sandpaper and diamond polishing agent, and then etched in a $2 \%$ aqueous nitric acid solution. The misorientation angle distribution and texture examination were carried out on an electron backscatter diffraction system (EBSD, Oxford instruments) with channel 5 data acquisition and analysis software. The samples prepared for EBSD were grinded and polished by ion-beam. According to ASTM E8-11 [30], room temperature tensile tests of the samples were carried out by an CMT5105 electronic universal testing machine at a speed of $2 \mathrm{~mm} / \mathrm{min}$. Specimens of sample EX, A1 and B1 for tensile tests had a gauge length of $30 \mathrm{~mm}$ and cross section of $\phi 6 \mathrm{~mm}$, and sample A2 and B2 for tensile tests had a gauge length of $10 \mathrm{~mm}$ and cross section of $\phi 2 \mathrm{~mm}$. Ultimate tensile strength (UTS), yield strength (YS) and elongation were obtained based on the average value of three tests. Hardness test was performed using an $\mathrm{Hv}-1000 \mathrm{z}$ Vickers microhardness tester with a load of $100 \mathrm{gf}$ and a dwell time of $10 \mathrm{~s}$. Hardness was obtained based on the average value of five tests. Finally, we proposed a bone-penetration test to simulate the surgical environment of orthopedic devices. The rods of sample A2 and sample B2 were processed into Kirschner wires with sharp three-arris edge as test materials and then were driven by an electronic hand drill to drill into an adult pig thigh bone.

\section{Results}

\subsection{Evolution of the Intermetallic Phase Distribution}

As shown in Fig. 1, the distribution of intermetallic phase was characterized by SEM micrography, and it can be seen that the microstructure of the as-extruded $\mathrm{Mg}-\mathrm{Zn}$ alloy consists of primary $\alpha-\mathrm{Mg}$ matrix, eutectic structure and fine secondary phase particles (Fig. 1a). Processed by the route A, eutectic structure is distorted and broken after six passes
Table 1 Processing state of Mg-6Zn samples

\begin{tabular}{lll}
\hline Sample code & Processing state & Diameter (mm) \\
\hline EX & Casting and extrusion & 15 \\
A1 & EX, ECAPed for 6 passes at $160^{\circ} \mathrm{C}$ & 15 \\
A2 & EX, ECAPed for 6 passes at $160^{\circ} \mathrm{C}$ and extruded at $180^{\circ} \mathrm{C}$ & 2.6 \\
B1 & EX, ECAPed for 6 passes at $320^{\circ} \mathrm{C}$ & 15 \\
B2 & EX, ECAPed for 6 passes at $320^{\circ} \mathrm{C}$ and extruded at $180{ }^{\circ} \mathrm{C}$ & 2.6 \\
\hline
\end{tabular}




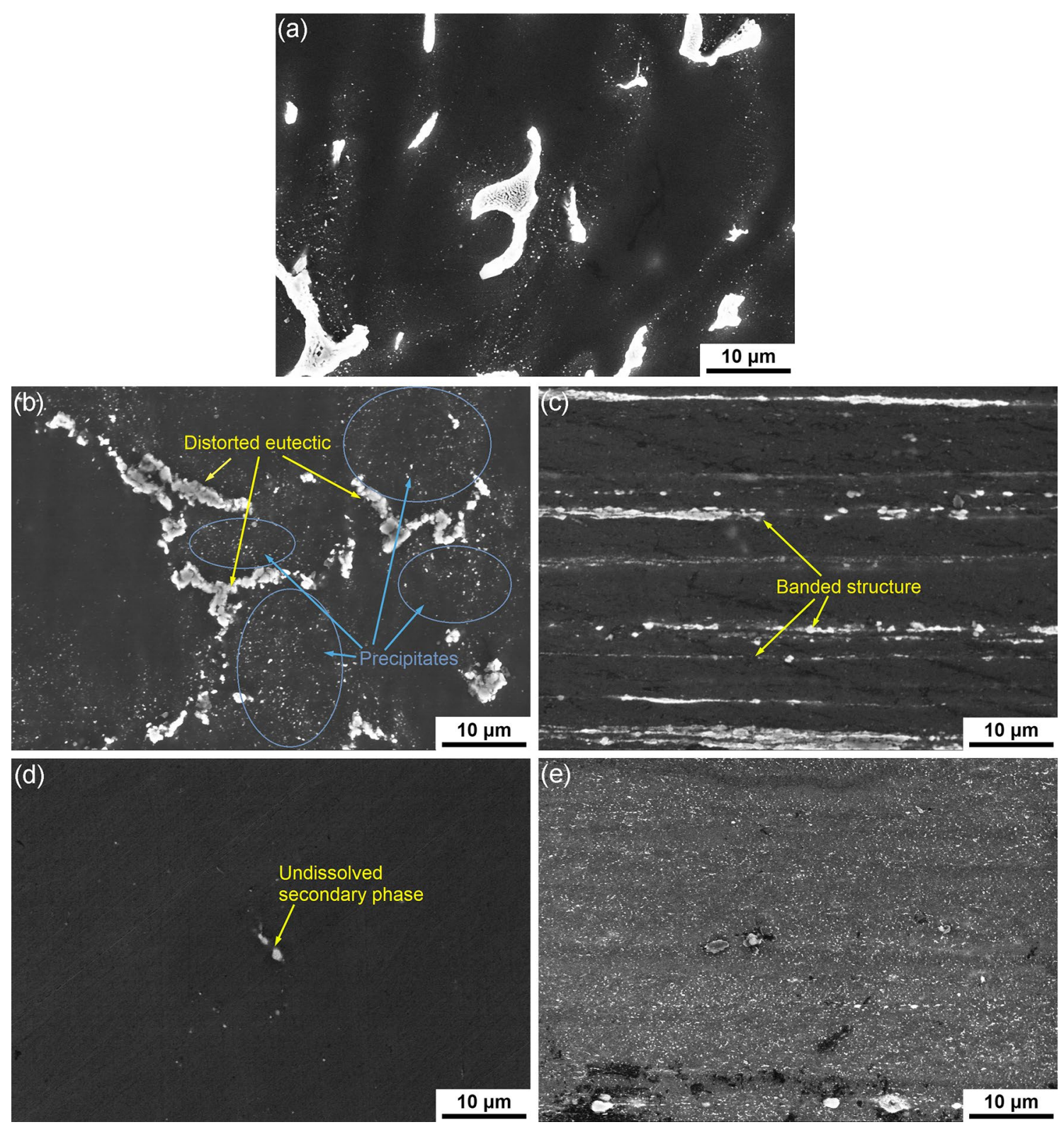

Fig. 1 SEM images of the tested Mg-6Zn alloy: a EX, b A1, c A2, d B1, e B2

ECAP at $160{ }^{\circ} \mathrm{C}$ (shown in Fig. 1b) and then the secondary phase is transformed into the clear banded structure distributed along the extruded direction after the post-ECAP extrusion at $180^{\circ} \mathrm{C}$ (shown in Fig. 1c). By contrast, the sixpass ECAP at $320^{\circ} \mathrm{C}$ results in fully solid solution with the exception of small minority undissolved secondary phase (shown in Fig. 1d), and the subsequent extrusion at $180{ }^{\circ} \mathrm{C}$ causes the massive and uniform precipitation of fine secondary phases (shown in Fig. 1e).

The morphology of precipitates is further observed by TEM micrography, as shown in Fig. 2. The broken eutectic structure after lower temperature ECAP is consisted of irregular-shaped secondary phase particles with the size of about $1 \mu \mathrm{m}$, and then turns into the band structure after the post-ECAP extrusion, as shown in Fig. 2a and b. There are small number of particles distributed sparsely in the vicinity of the banded structure in the sample A2, which have spherical shape and the average diameter of about $20 \mathrm{~nm}$, as shown in Fig. 2c. By comparison, the TEM micrographs of A1 and $A 2$, it can be seen that the subsequent extrusion causes the morphology changing of the secondary phase particles and induces the formation of clear banded structure but has little effect in precipitation within the matrix. However, high-temperature ECAP can eliminate completely the segregation of $\mathrm{Zn}$ element. Figure $2 \mathrm{~d}$ shows the microstructure of regular-arranged rods array mixed up with interspersed 

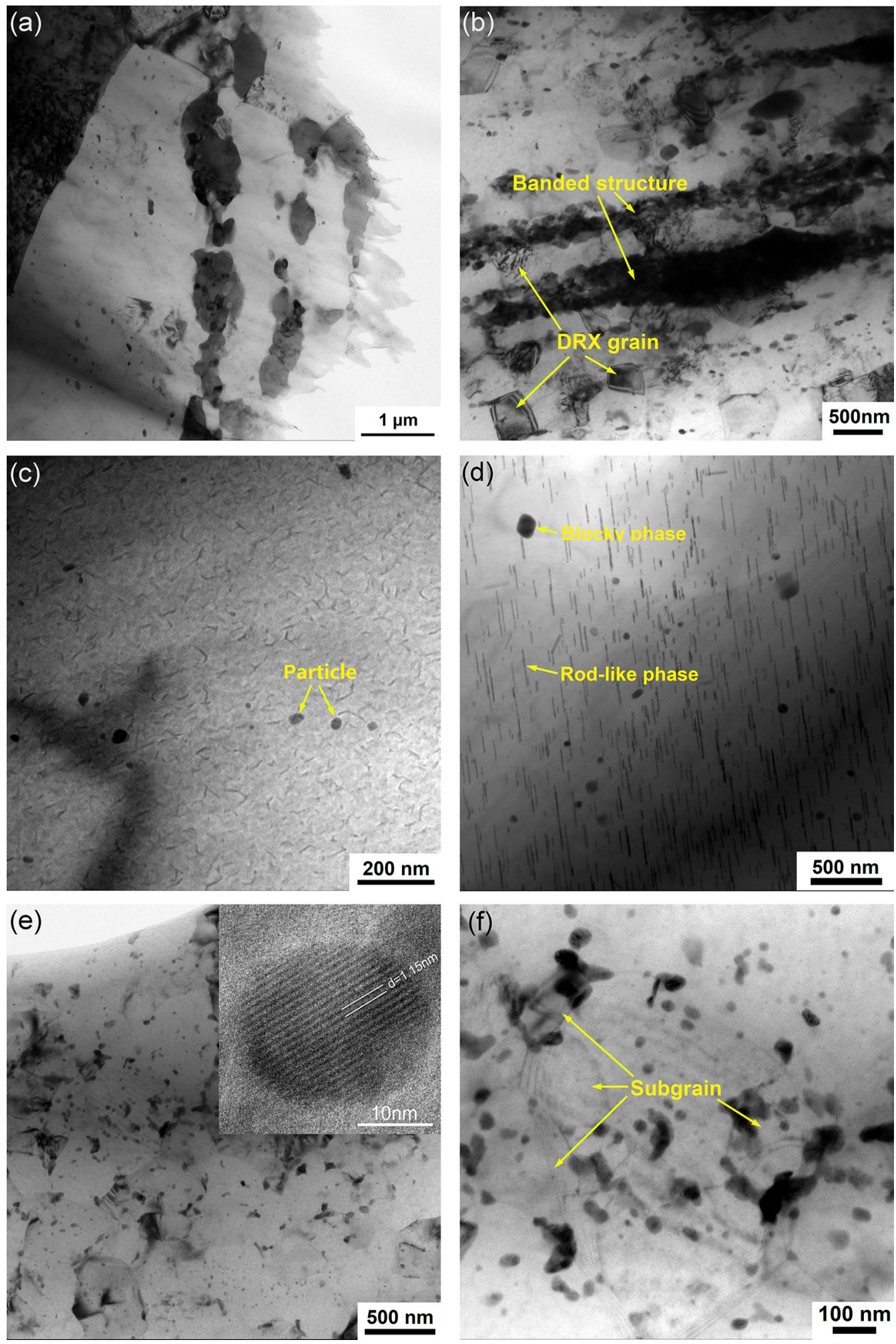

Fig. 2 TEM images of the tested Mg-6Zn alloy: a A1, b, c A2, d B1, e, f B2

blocky particles, very similar to the typical microstructure of $\mathrm{Mg}-\mathrm{Zn}$ alloys after solid solution treatment. These rod-like precipitates with the length of $100-200 \mathrm{~nm}$ were generally identified as the $\beta^{\prime}-\mathrm{Mg}_{4} \mathrm{Zn}_{7}$ phase in the previous studies, and the blocky particles were regarded as $\beta^{\prime \prime}-\mathrm{MgZn}_{2}$ phase [31-33]. Furthermore, as shown in Fig. 2e and f, the rod-like 
precipitates observed in the sample B1 completely disappear and are replaced by spherical precipitates with the diameter from 10 to $50 \mathrm{~nm}$ after the subsequent extrusion. Although these nanoprecipitates are too small to be identified by the selected area electron diffraction (SAED), the high-resolution TEM image (the inset in Fig. 2e) indicates that the nanoparticles possess the structure of $\beta^{\prime \prime}-\mathrm{MgZn}_{2}$ phase, showing the (313) plane of $\mathrm{MgZn}_{2}$ phase with the interplanar spacing of $1.15 \mathrm{~nm}$. Moreover, there are some sub-grains existing within the $\alpha-\mathrm{Mg}$ grains with the size of about $200-300 \mathrm{~nm}$ from the larger-magnification micrograph, as shown in Fig. 2f. It is apparent that the sample B2 has much higher uniformity and more nanoparticles than the sample A2. In addition, it is noted that no dislocation is clearly observed in the TEM images of both the samples A2 and B2.

\subsection{Difference of Grain Size, Dislocation Density and Texture}

In addition to intermetallic phases, other microstructural characteristics such as grain size, dislocation density and texture are also essential to investigate the difference of effects between two technology routes. EBSD is performed on the transversal surface of the tested samples A2 and $\mathrm{B} 2$, where only $\alpha-\mathrm{Mg}$ grains are marked. For each sample, at least $140 \alpha-\mathrm{Mg}$ grains are analysed to achieve credible results with statistical significance, as shown in Fig. 3.

The grain orientation mapping indicates, firstly, the great difference of grain size in two samples, as shown in Fig. 3a and $\mathrm{c}$. The corresponding grain size statistics show that the average grain size of $2.3 \mu \mathrm{m}$ in sample A2 is far less than that of $10.8 \mu \mathrm{m}$ in sample B2, as shown in Fig. $3 \mathrm{~b}$ and d, which is mainly because of the temperature difference during the ECAP process. Secondly, both A2 and B2 samples have uniform and equiaxial grains, as well as straight grain boundaries. It means that the fully dynamical recrystallization has happened after the last extrusion at $180{ }^{\circ} \mathrm{C}$, and the integration of ECAP and extrusion can provide enough strain to eliminate the inhomogeneity of grain size [34, 35].

Figure $3 \mathrm{e}$ and g show the local misorientation mapping with different processing routes. In these large area mapping (LAM) maps, the black and light-green lines present high-angular grain boundaries (HAGBs) and low-angular grain boundaries (LAGBs), respectively. According to the kernel average misorientation (KAM) method, the local crystal orientations could be used to measure the geometrical necessary dislocations (GND). However, the very low densities of LAGBs are observed in the samples A2 and $\mathrm{B} 2$ and the statistics histograms show that the difference in the distribution of LAGBs between A2 and B2 is very small, as shown in Fig. $3 \mathrm{f}$ and $\mathrm{h}$. This suggests that there is very low density of dislocation in both samples, which also can be verified from the former TEM images. Figure $3 i$ and $j$ show the pole figures, and the extrusion direction (ED) is vertical to the plane of projection in figures. Both samples show the same texture components, similar to the $\{11-20\}<0001>$ fiber texture and the texture intensity of A2 is 10.77 , higher than that of 9.51 in $\mathrm{B} 2$.

Generally, the dislocation density and texture intensity of the sample A2 are very close the level of B2. The primary microstructural differences between $\mathrm{A} 2$ and $\mathrm{B} 2$ are the distribution of solute atom and the grain size and other factors are neglectable.

\subsection{Mechanical Properties}

Figure 4a shows the yield strength (YS), ultimate tensile strength (UTS) and elongation (El.) of tested $\mathrm{Mg}$ $6 \mathrm{Zn}$ alloy. Processed through route A, the YS and UTS after low-temperature ECAP for six passes are improved to $275 \mathrm{MPa}$ and $340 \mathrm{MPa}$, respectively. The subsequent extrusion at $180^{\circ} \mathrm{C}$ has slight negative impact on both the strengths and the ductility for that processed via route A. The YS, UTS and elongation of sample A2 decrease to $200 \mathrm{MPa}, 330 \mathrm{MPa}$ and $10.5 \%$, respectively. By contrast, the high-temperature ECAP results in the deceasing of strengths, but then the strengths dramatically increase after subsequent extrusion. The YS of $355 \mathrm{MPa}$ and the UTS of $405 \mathrm{MPa}$, as well as the elongation of $17.5 \%$ are obtained in sample B2. Figure $4 \mathrm{~b}$ shows the Vickers hardness of the tested $\mathrm{Mg}-6 \mathrm{Zn}$ alloys. The hardness of the $\mathrm{Mg}-6 \mathrm{Zn}$ alloy processed by route A is gradually improved and the sample A2 has the second highest hardness of 87.9. The highest hardness of 106.5 is obtained in the sample B2. According to the results of tension test at room temperature and hardness test, it is feasible that the ultrahigh-strength $\mathrm{Mg}-6 \mathrm{Zn}$ alloy is able to be prepared by the route $\mathrm{B}$, the strengthening strategy for $\mathrm{Mg}-\mathrm{Zn}$ alloy we conceived earlier.

\subsection{Bone-penetration test}

The bone-penetration test was conducted to assess the ability of resisting the deformation now that the ultrahigh strength has been achieved in $\mathrm{Mg}-6 \mathrm{Zn}$ alloy sample B2. The thin rods of sample A2 and sample B2 were machined into Kirschner wire with a sharp trigone end, as shown in Fig. 5a. The result of drilling is displayed in Fig. 5b. The Kirschner wire fabricated form sample B2 can drill successfully into the adult pig thigh bone but that of A2 fails. It can be seen that the end of $\mathrm{B} 2$ remains sharp after drilling test, as shown in Fig. 5c, while the end of A2 is distorted and blunted, as shown in Fig. 5d. 

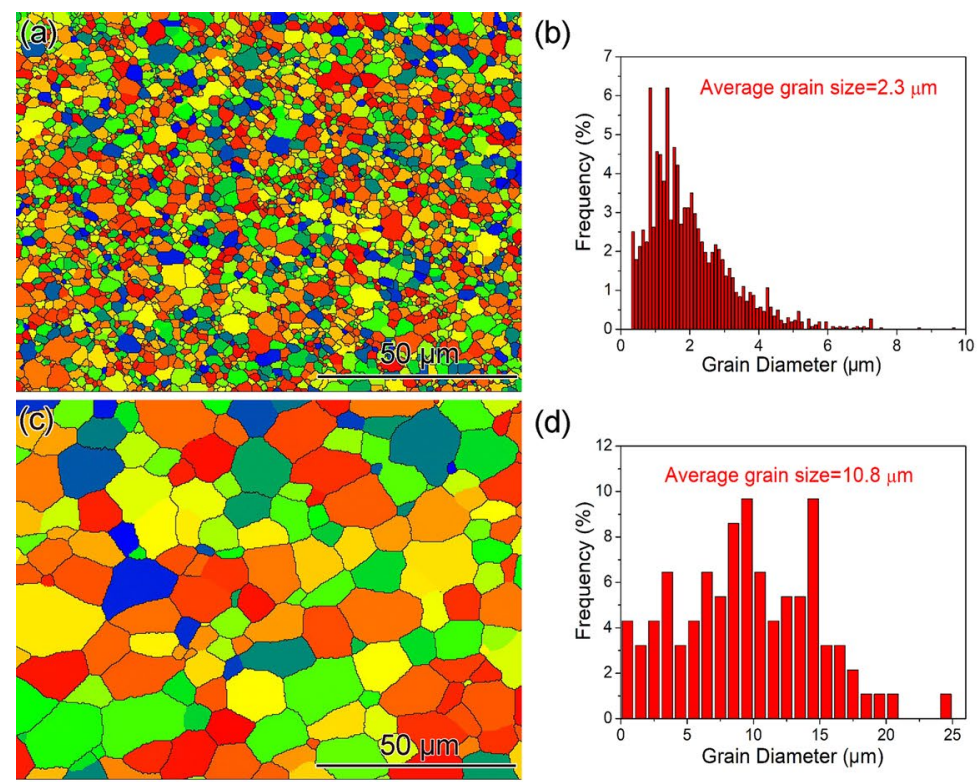

(d)
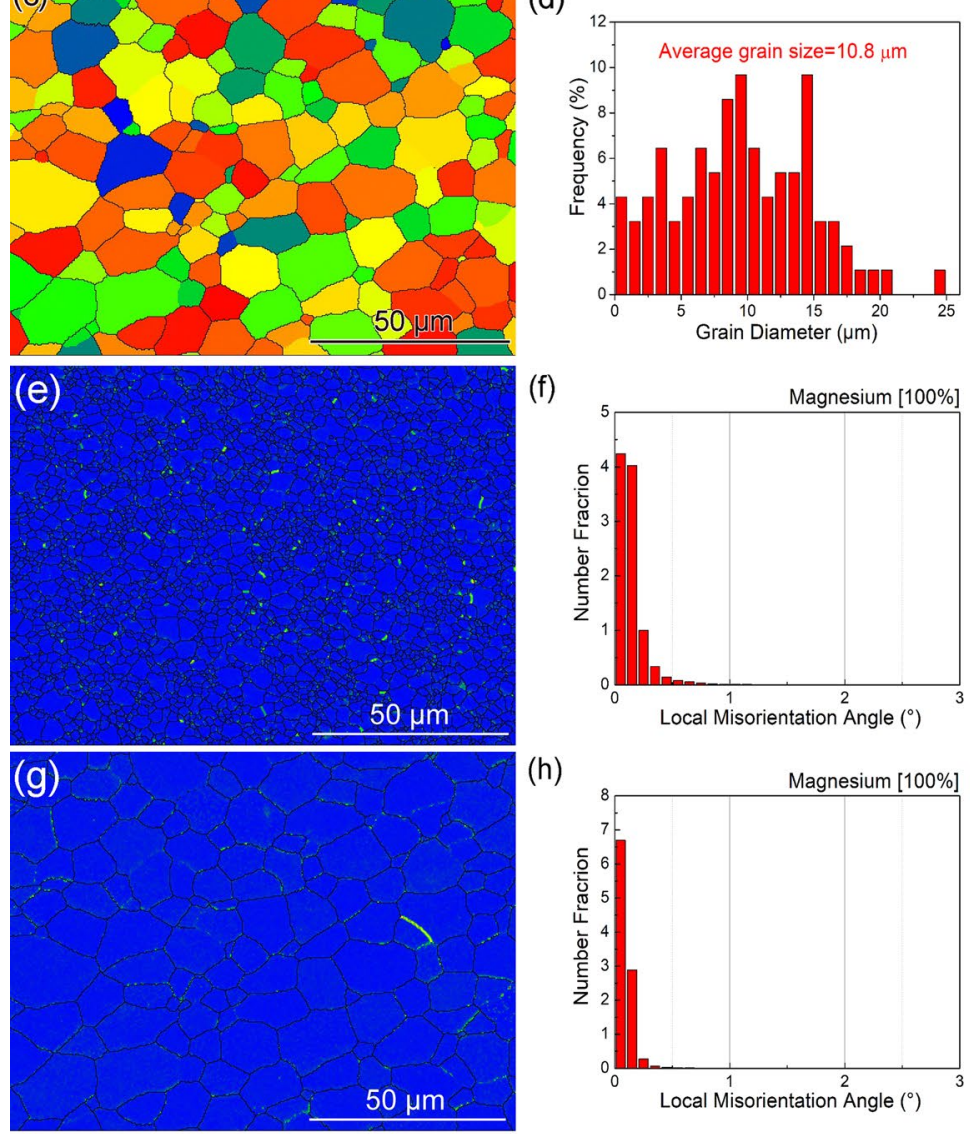

(h)
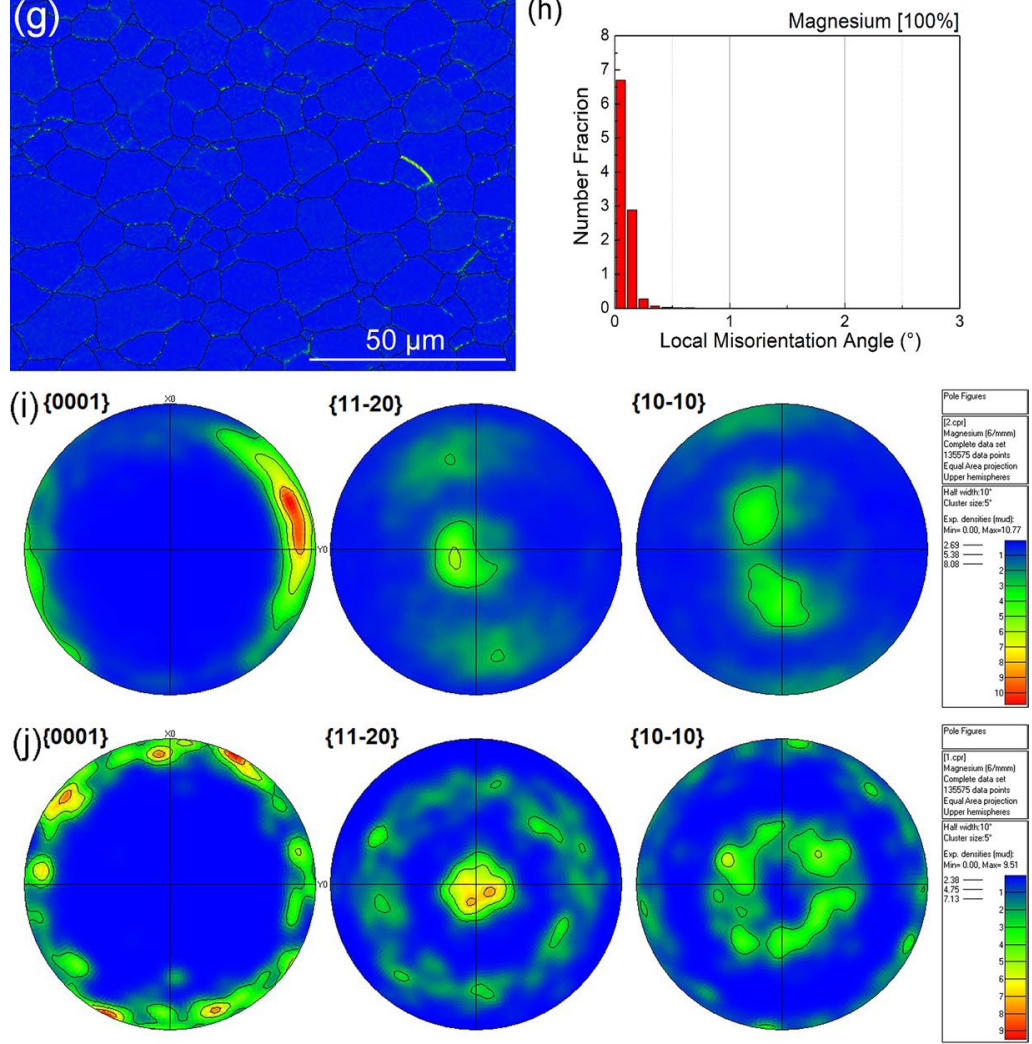
4Fig. 3 EBSD analysis results of samples A2 and B2. a, b Grain orientation mapping and grain size histogram of A2, $\mathbf{c}, \mathbf{d}$ grain orientation mapping and grain size histogram of $\mathrm{B} 2, \mathbf{e}, \mathbf{f}$ local misorientation mapping and statistics of $\mathrm{A} 2, \mathbf{g}, \mathbf{h}$ local misorientation mapping and statistics of $\mathrm{B} 2$, i pole figures of $\mathrm{A} 2, \mathbf{j}$ pole figures of $\mathrm{B} 2$

\section{Discussion}

\subsection{Precipitation Behavior}

The important and noteworthy microstructural characterization in the sample B2 was homogenization and high-density nanoprecipitation of $\mathrm{MgZn}_{2}$ phase. The fully homogenization is the prerequisite for high-density nanoprecipitation. The high-temperature SPD could clearly accelerate homogenization and promote the single-phase structure in $\mathrm{Mg}-6 \mathrm{Zn}$ alloy when the temperature is up to the melting point of the intermetallic phase (about $325^{\circ} \mathrm{C}$ ) $[36,37]$. After that, the increasing supersaturation of the solute resulted in the spontaneous precipitation of massive directional aligned rod-like nano-sized $\mathrm{Mg}_{4} \mathrm{Zn}_{7}$ phase from the single-phase supersaturate solid solution. The rod-like intermetallic phase plays a key role in inducing nano-sized spherical precipitates during the extrusion process because the long-rod particle might break into short-rod particles during extrusion and turn into spherical particles later, and the solution diffusion is involved possibly in their spheroidization and transformation [26, 38]. Another study revealed that the rod nanoparticles could also directly turn into spherical in ZK60 magnesium alloy as the aspect ratio decreased at very high strain rate [38]. Although the dynamic transformation mechanism is ambiguous, the rod-like particles are certainly a benefit for the quick and massive nanoprecipitation as precursors under subsequent large deformation at low temperatures. However, high-temperature ECAP processing cannot suppress the growth of $\alpha-\mathrm{Mg}$ matrix grains as it dissolves secondary phase and inevitably leads to larger grains in the final thin bars.

In contrast, the low-temperature ECAP and extrusion processing are effective to produce ultrafine grained microstructure. However, it could not reduce the dimension of the second-phase particles and eliminate the segregation of the solute atoms. For instance, large bulk secondary phase changed into the clear banded structures after the ECAP process at $160{ }^{\circ} \mathrm{C}$ in this study, which results in the lower solid solution of zinc in $\alpha-\mathrm{Mg}$ matrix than that processed by high-temperature ECAP and extrusion. Therefore, these are only a small number of precipitates existing in the matrix and very few are observed in the region far away from the banded structures after the subsequent extrusion.

\subsection{Comparison of Mechanical Properties with Literature Results}

Grain refinement is considered as one of the most effective methods to strengthen magnesium alloys and this is principal because the slope $k$ in the Hall-Patch equation $\left(\sigma_{\mathrm{y}}=\sigma_{0}+k d\right.$ $-1 / 2$ ) can be particularly high. The $k$ coefficient in Mg alloys was estimated to amount to above $200 \mathrm{MPa}(\mu \mathrm{m})^{1 / 2}$ in literature [39-41]. Moreover, Caceres et al. [42] found that the $k$ value was strongly associated with the $\mathrm{Zn}$ content and it could reach $660 \mathrm{MPa}(\mu \mathrm{m})^{1 / 2}$ for the $\mathrm{Mg}-2.3$ at. $\% \mathrm{Zn}$ alloy (approximate to $\mathrm{Mg}-6 \mathrm{wt} \% \mathrm{Zn}$ ) when the grain size was over $50 \mu \mathrm{m}$. This is probably a good explanation of why the researchers were keen on refining grains in $\mathrm{Mg}$ alloys.

Table 2 summarizes the data on mechanical properties and microstructural characteristics of high strength $\mathrm{Mg}-6 \mathrm{Zn}$ based alloys after different kinds of thermo-mechanical processing. It suggests the consistent evidence of differentiated results from the two strategies. The combination of ECAP and extrusion is effective to produce the high-strength $\mathrm{Mg}$ alloy bar for now, such as route A and route B in this study, but the technical details decide the mechanism and its strengthening effects. The data listed in Table 2 show that limiting strengths in $\mathrm{Mg}$ $6 \mathrm{Zn}$ alloy processed by grain refinement processing are about $310 \mathrm{MPa}$ in YS or $360 \mathrm{MPa}$ in UTS. However, the route B in this study can easily make the strengths exceed the strength limit. What matters for the strengthening of $\mathrm{Mg}-\mathrm{Zn}$ alloys is a large number of nanoprecipitates rather than ultrafine grains whether the nanoprecipitates are introduced by $\mathrm{T} 6$ heat treatment or low-temperature deformation [28, 29].

The hardening effect of grain refinement comes from that the grain boundaries obstacle against the moving of dislocations. However, the grain refinement strengthening of magnesium alloys is restricted by their lower stacking fault energy. On the one hand, the lower stacking fault energy results in the dislocations piled on grain boundary to be easily to recovery by cross-slip. On the other hand, the dimension of dynamic recrystallization grain is correlated with the size of sub-grain, which is depended on the width of extended dislocation. According to the records listed in Table 2, the minimum average grain size is $0.6 \mu \mathrm{m}$, which ought to have reached or been close to the limit of grain refinement.

Instead, the hardening effect of the precipitation comes from the particle's obstacle against the dislocations. The Orowan increment in critical resolved shear stress (CRSS) produced by the need for dislocations to by-pass these obstacles is given as [43]:

$\Delta \tau=\frac{G b}{2 \pi \lambda \sqrt{1-v}} \ln \frac{d_{p}}{b}$,

where $\Delta \tau$ is the increment in CRSS due to dispersion strengthening, $G$ the shear modulus of the magnesium 

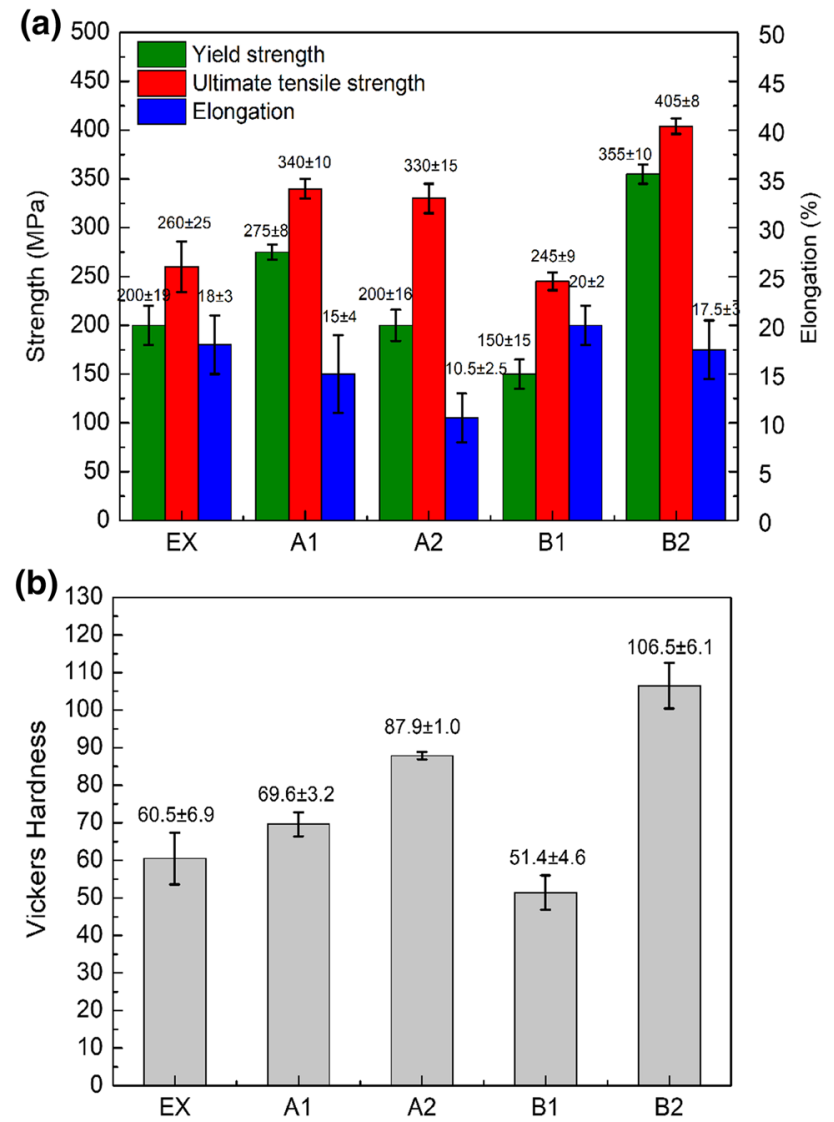

Fig. 4 Histograms of tensile mechanical properties a, hardness $\mathbf{b}$ of the tested alloys

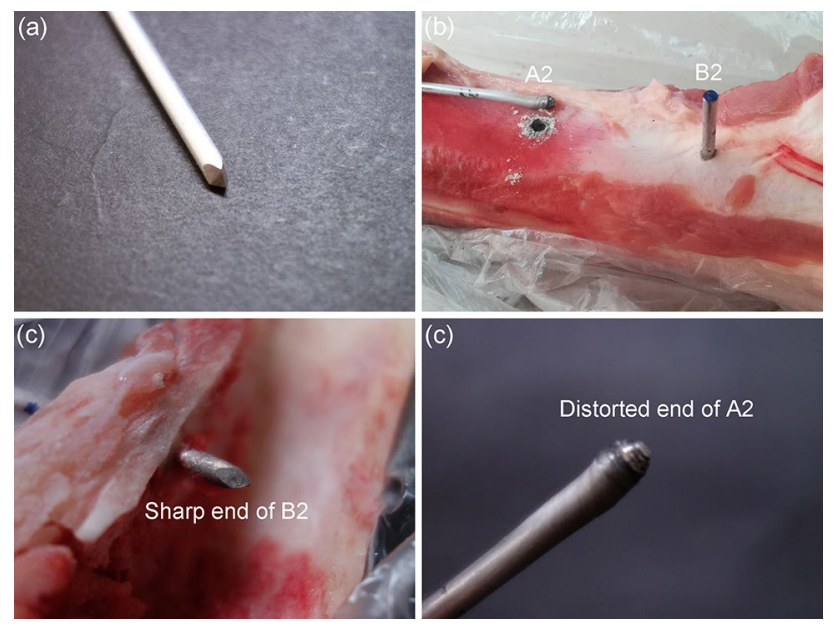

Fig. 5 Photos of the bone-penetration test: a the undrilled Kirschner wire, $\mathbf{b}$ the result after drilling, $\mathbf{c}$ the drilled Kirschner wire from sample B2, $\mathbf{d}$ the drilled Kirschner wire from sample A2

matrix phase, $b$ the magnitude of the Burgers vector of the slip dislocations, $\nu$ the Poisson's ratio, $\lambda$ the effective planar inter-obstacle spacing, and $d_{p}$ the mean planar diameter of the point obstacles. Nie et al. [43] developed an Orowan equation for spherical precipitates, the effective planar interprecipitate spacing, $\lambda$, is calculated as:

$\lambda=\left(\frac{0.779}{\sqrt{f}}-0.785\right) d_{t}$,

where $f$ is the volume fraction of precipitates, $d_{t}$ is the diameter of spherical precipitates. The increment in YS due to Orowan strengthening, $\Delta \sigma$, is then obtained from the following relation:

$\Delta \sigma=M \Delta \tau$,

where $M$ is Taylor factor, equals to 4.5 for the randomly textured Mg. Substituting Eqs. (1) and (2) into Eq. (3), and presuming the other parameters are constants, the relationship of $\Delta \sigma$ and the mean planar diameter of the point obstacles $d_{p}$ are given as:

$\Delta \sigma \in \frac{\ln \left(d_{p}\right)}{d_{p}}$.

This relational expression shows that the $\Delta \sigma$ will be increased by about 11 times as the $d_{p}$ is reduced by one order of magnitude when the $d_{p}$ is less than one micrometer. Thus, the dispersion strengthening mechanism provides an opportunity to significantly improve the strengths to a surprising level when the specially designed technique is used to manufacture a tremendous number of nanoprecipitates.

\subsection{Correlation Between Mechanical Properties and Microstructure}

The strength improvement in sample $\mathrm{B} 2$ is a crucial progress for the orthopedic application of $\mathrm{Mg}-6 \mathrm{Zn}$ alloy in case of no successful bone-penetration test on $\mathrm{Mg}-\mathrm{Zn}$ alloys before. More importantly, the sample processed by grain refinement, such as the sample A2 in this study, cannot pass the penetration test. It is apparent that the strength improvement can only be attributed to high-density nano precipitates because the present results illustrate that the texture, work hardening and grain size in sample B2 have a less strengthening effect than that in sample A2.

The strengths and hardness of the B2 Kirschner wire are improved to above a certain threshold so that the thin rod could withstand high stress during the drilling process. In contrast, the sample processed by the common strategies (i.e., the route A) is vulnerable to the bone even though its strength has been increased substantially. In light of this, it can be considered as a crucial progress in the aspect of mechanical properties of $\mathrm{Mg}-\mathrm{Zn}$ alloys.

The average grains size depended strongly on the extrusion temperature during the multi-pass ECAP processing 
Table 2 Mechanical properties and average grain diameters of the $\mathrm{Mg}-6 \mathrm{Zn}$ based alloys after different kinds of thermo-mechanical processing

\begin{tabular}{|c|c|c|c|c|c|c|c|}
\hline & YS (MPa) & UTS (MPa) & El. $(\%)$ & Eq.dia.* $(\mu \mathrm{m})$ & Material & Process & Refs. \\
\hline 1 & 273 & 300 & 30 & 0.6 & ZK60 & $\mathrm{ECAP}, 4 p$ at $523 \mathrm{~K}+, 4 p$ at $473 \mathrm{~K}+4 p$ at $423 \mathrm{~K}$ & [19] \\
\hline 2 & 270 & 326 & 5.4 & 1 & ZK60 & Rolling, $4 p$ at $623 \mathrm{~K}, 4.3-1 \mathrm{~mm}$ & [20] \\
\hline 3 & 175 & 266 & 31.9 & 0.8 & ZK60 & $\mathrm{ECAP}, 4 p$ at $513 \mathrm{~K}+4 p$ at $453 \mathrm{~K}$ & [21] \\
\hline 4 & 310 & 351 & 17.1 & 1.7 & ZK60 & Direct extrusion +ECAP, $2 p$ at $623 \mathrm{~K}$ & [22] \\
\hline 5 & 215 & 289 & 37.8 & 1.4 & ZK60 & Cyclic extrusion-compression, $4 p$ at $503 \mathrm{~K}$ & {$[23]$} \\
\hline 6 & 286 & 338 & 30 & 1.4 & ZK60 & High-ratio differential speed rolling, $1 p$ at $473 \mathrm{~K}$ & [24] \\
\hline 7 & 260 & 371 & 18.5 & 1 & ZK60 & $\mathrm{ECAP}, 4 p$ at $523 \mathrm{~K}+2 p$ at $473 \mathrm{~K},+2 p$ at $423 \mathrm{~K}$ & {$[25]$} \\
\hline 8 & 258 & 359 & 20.1 & 1.2 & $\mathrm{Mg}-5 \mathrm{Zn}-1 \mathrm{Mn}$ & HSRR, $1 p$ at $573 \mathrm{~K}, 10-2 \mathrm{~mm}$ & {$[26]$} \\
\hline 9 & 275 & 340 & 15 & 1.9 & $\mathrm{Mg}-6 \mathrm{Zn}$ & ECAP, $6 p$ at $433 \mathrm{~K}$ & This study \\
\hline 10 & 190 & 330 & 10.5 & 2.3 & $\mathrm{Mg}-6 \mathrm{Zn}$ & ECAP, $6 p$ at $433 \mathrm{~K}+$ extrusion, at $453 \mathrm{~K}$ & This study \\
\hline 11 & 355 & 405 & 17.5 & 10.8 & $\mathrm{Mg}-6 \mathrm{Zn}$ & ECAP, $6 p$ at $593 \mathrm{~K}+$ extrusion, at $453 \mathrm{~K}$ & This study \\
\hline 12 & 390 & 440 & 8.3 & - & ZK60 & Twin roll cast + rolling, $6 p$ at $573 \mathrm{~K}, 3.2-0.5 \mathrm{~mm}$ & [28] \\
\hline 13 & 333 & 420 & 16.1 & 6.8 & ZK60 & $\begin{array}{l}\text { Twin roll cast +rolling, } 6 p \text { at } 573 \mathrm{~K}, 3.2-0.5 \mathrm{~mm}+\mathrm{T} 6,3 \mathrm{~h} \\
\text { at } 648 \mathrm{~K} \text { and } 10 \mathrm{~h} \text { at } 448 \mathrm{~K}\end{array}$ & [28] \\
\hline 14 & 396 & 440 & 9 & 7 & ZK60 & $\begin{array}{l}\text { ECAP, } 12 p 573 \mathrm{~K}+\text { rolling, total reduction } 30 \% \text { at room } \\
\text { temperature }\end{array}$ & [29] \\
\hline
\end{tabular}

*Eq.dia. is the abbreviation of equivalent grain diameter

[37]. The six passes ECAP at $160^{\circ} \mathrm{C}$ produced the ultrafine grains by dynamic recrystallization, as well as strong texture and high-density dislocations. However, the follow-up extrusion at $180^{\circ} \mathrm{C}$ inevitably caused the loss of mechanical properties of the ultrafine-grained sample A2 because the elevating of deformation temperature lowered these effects. On contrary, the high-temperature ECAP tended to construct a single-phase supersaturate solid solution microstructure and the subsequent extrusion dramatically improved the mechanical properties in the sample B2 by causing the dynamic precipitation of nano-size phase. By comparing the route $\mathrm{A}$ and route $\mathrm{B}$, the difference between two strategies can be boiled down to that they strengthen the $\mathrm{Mg}-\mathrm{Zn}$ alloy in two very different ways, and the latter way is undoubtable more effective and more promising.

It is worth exploring why the grain refinement cannot have the same strengthening effects with nanoprecipitation as the results shown in this study. Generally, shape, size and distribution of precipitates have dramatic effects on the strengthening. The extensive researches reported that the ultrafine-grained $\mathrm{Mg}-6 \mathrm{Zn}$ or ZK60 alloys have spherical or rod nanoprecipitates, but the segregation in grain boundaries and nonuniform distribution of the particle phase can also be observed. In addition, it may also be attributed to the reduced dispersion strengthening caused by the coarsening of precipitates during the multiple-pass plastic deformation. The Gibbs-Thomson effect illustrates that the nanoprecipitate is thermodynamically unstable due to the dependence of the corrected solubility limit of the solute in the matrix on the radius of precipitation particle $[44,45]$. It means that the smaller precipitates prefer to dissolve into the matrix and then the solute atoms diffuse and segregate on the surface of the bigger precipitates or on the grain boundaries. Moreover, it will be accelerated by deformation and elevated temperatures. As a consequence, it can be concluded that the mechanical properties can get great improvement only when the latter extrusion after full homogenization is carried out at a higher strain rate and a lower temperature.

Based on above discussions, it is considered for $\mathrm{Mg}-\mathrm{Zn}$ alloys that promoting the microstructure of nanoprecipitation followed by fully homogenization is a more effective strengthening method than merely grain refinement. In other words, the combination technology of deformation-induced homogenization treatment and low-temperature large deformation processing is more competitive and productive than the previous desultory attempts for the development of highmechanical properties $\mathrm{Mg}-\mathrm{Zn}$ alloys.

\section{Conclusions}

In this study, a comparison with the two processing routes based on different strategies shows vastly difference of microstructures and mechanical properties in $\mathrm{Mg}-6 \mathrm{Zn}$ alloys and results confirm that thermal-mechanical treatment has great potentiality in strengthening $\mathrm{Mg}-\mathrm{Zn}$ alloys. The following conclusions can be drawn:

(1) The improved strategy based on deformation-induced nanoprecipitation (six-pass ECAP at $320^{\circ} \mathrm{C}$ and extrusion at $180{ }^{\circ} \mathrm{C}$ ) provided the yield strength of $355 \mathrm{MPa}$ and the ultimate tensile strength of $405 \mathrm{MPa}$ and the 
elongation of $17.5 \%$, as well as the Victors hardness of 106.5, which are much higher than the sample processed by comparative strategy.

(2) The ultrahigh mechanical properties were principally depended on a large number of uniformly distributed $\mathrm{MgZn}_{2}$ phase precipitates with the diameter $10 \mathrm{~nm}$ to $50 \mathrm{~nm}$ instead of grain refinement, strong textured microstructure and working hardening.

(3) The improvement of mechanical properties is a crucial factor for $\mathrm{Mg}-6 \mathrm{Zn}$ alloy Kirschner wire penetrating through the adult pig thigh bone, which signs the breakthrough of high strength $\mathrm{Mg}-\mathrm{Zn}$ alloy orthopedic devices.

Acknowledgements This study was financially supported by the National Natural Science Foundation of China (No. 51901068).

\section{References}

[1] F. Witte, N. Hort, C. Vogt, S. Cohen, K.U. Kainer, R. Willumeit, F. Feyerabend, Curr. Opin. Solid State Mater. Sci. 63, 12 (2008)

[2] F. Witte, Acta Biomater. 1680, 6 (2010)

[3] M.P. Staiger, A.M. Pietak, J. Huadmai, G. Dias, Biomaterials 1728, 27 (2006)

[4] H. Li, Y. Zheng, L. Qin, Prog. Nat. Sci. 414, 24 (2014)

[5] Y. Shao, R.C. Zeng, S.Q. Li, L.Y. Cui, Y.H. Zou, S.K. Guan, Y.F. Zheng, Acta Metall. Sin. (Engl. Lett.) 615, 33 (2020)

[6] M. Němeca, A. Jäger, K. Tesař, V. Gärtnerová, Mater. Charact. 69, 134 (2017)

[7] Y. Chen, Z. Xu, C. Smith, J. Sankar, Acta Biomater. 4561, 10 (2014)

[8] S. Zhang, X. Zhang, Ch. Zhao, J. Li, Y. Song, Ch. Xie, H. Tao, Y. Zhang, Y. He, Y. Jiang, Y. Bian, Acta Biomater. 626, 6 (2010)

[9] H. Liu, H. Huang, J.P. Sun, C. Wang, J. Bai, A.B. Ma, X.H. Chen, Acta Metall. Sin. (Engl. Lett.) 32, 269 (2019)

[10] H. Huang, H. Liu, L.S. Wang, Y.H. Li, S.O. Agbedor, J. Bai, F. Xue, J.H. Jiang, Acta Metall. Sin. (Engl. Lett.) 33, 1191 (2020)

[11] S. Cai, T. Lei, N. Li, F. Feng, Solid State Phenom. 381, 217 (2015)

[12] Y. Song, E.H. Han, D. Shan, C.D. Yim, B.S. You, Corro. Sci. 238, $60(2012)$

[13] Y. Song, E.H. Han, D. Shan, C.D. Yim, B.S. You, Corro. Sci. 322, 65 (2012)

[14] E. Koç, M.B. Kannan, M. Ünal, E. Candan, J. Alloys Compd. 291, $648(2015)$

[15] H. Liu, H. Huang, C. Wang, J.P. Sun, J. Bai, F. Xue, A.B. Ma, X.B. Chen, JOM 71, 9 (2019)

[16] H. Liu, J. Ju, X.W. Yang, J.L. Yan, D. Song, J.H. Jiang, A.B. Ma, J. Alloys Compd. 704, 509 (2017)
[17] S.Y. Jin, H.Y. Liu, R.Z. Wu, F. Zhong, L.G. Hou, J.H. Zhang, Mater. Sci. Eng., A 139611, 788 (2020)

[18] J.H. Wang, L. Xu, R.Z. Wu, J. Feng, J.H. Zhang, L.G. Hou, M.L. Zhang, Acta Metall. Sin. (Engl. Lett.) 490, 33 (2020)

[19] E. Mostaed, M. Hashempour, A. Fabrizi, D. Dellasega, M. Bestetti, F. Bonollo, M. Vedani, J. Mech. Behav. Biomed. 307, 37 (2014)

[20] X. Gong, S.B. Kang, J.H. Cho, S. Li, Mater. Charact. 183, 97 (2014)

[21] Y. He, Q. Pan, Y. Qin, X. Liu, W. Li, Y. Chiu, J.J.J. Chen, J. Alloys Compd. 605, 492 (2010)

[22] D. Orlov, G. Raab, T.T. Lamark, M. Popov, Y. Estrin, Acta Mater. 375, 59 (2011)

[23] J. Lin, Q. Wang, L. Peng, H.J. Roven, J. Alloys Compd. 441, 476 (2009)

[24] W.J. Kim, M.J. Kim, J.Y. Wang, Mater. Sci. Eng., A 322, 527 (2009)

[25] Y. Yuan, A. Ma, X. Gou, J. Jiang, G. Arhin, D. Song, H. Liu, Mater. Sci. Eng., A 125, 677 (2016)

[26] C. Chen, J. Chen, H. Yan, B. Su, M. Song, S. Zhu, Mater. Des. 58, 100 (2016)

[27] S.J. Meng, H. Yu, S.D. Fan, Q.Z. Li, S.H. Park, J.S. Suh, Y.M. Kim, X.L. Nan, M.Z. Bian, F.X. Yin, W.M. Zhao, B.S. You, K.S. Shin, Acta Metall. Sin. (Engl. Lett.) 145, 32 (2019)

[28] H. Chen, S.B. Kang, H. Yu, J. Cho, H.W. Kim, G. Min, J. Alloys Compd. 324, 476 (2009)

[29] Y. Yuan, A. Ma, X. Gou, J. Jiang, F. Lu, D. Song, Y. Zhu, Mater. Sci. Eng., A 45, 630 (2015)

[30] ASTM Standard E8-11, ASTM International (West Conshohocken, PA, 2011). www.astm.org

[31] L.Y. Wei, G.L. Dunlop, H. Westengen, Metall. Mater. Trans. A 1705, 26 (1995)

[32] X. Gao, J.F. Nie, Scr. Mater. 655, 57 (2007)

[33] A. Singh, A.P. Tsai, Scr. Mater. 941, 57 (2007)

[34] H. Liu, C. Sun, C. Wang, Y.H. Li, J. Bai, F. Xue, A.B. Ma, J.H. Jiang, J. Mater. Sci. Technol. 59, 61 (2020)

[35] H. Huang, H. Liu, C. Wang, J.P. Sun, J. Bai, F. Xue, J.H. Jiang, A.B. Ma, J. Magn. Alloys 7, 617 (2019)

[36] K. Yan, H. Liu, N. Feng, J. Bai, H. Cheng, J. Liu, F. Huang, J. Magn. Alloys 305, 7 (2019)

[37] J. Yan, Z. Qin, K. Yan, Metals 841, 8 (2018)

[38] Y. Yang, Z. Wang, L. Jiang, J. Alloys Compd. 566, 705 (2017)

[39] E.F. Emely, Principles of Magnesium Technology (Pergamon Press, Oxford, 1966), p. 483

[40] Y.N. Wang, J.C. Huang, Mater. Trans. 184, 48 (2007)

[41] H. Chen, H. Yu, S.B. Kang, J.H. Cho, G. Min, Mater. Sci. Eng., A 1236, 527 (2010)

[42] C.H. Caceres, G.E. Mann, J.R. Griffiths, Metall. Mater. Trans. A 1950, 42 (2011)

[43] J.F. Nie, Scr. Mater. 1009, 48 (2003)

[44] M. Perez, Scr. Mater. 709, 52 (2005)

[45] L. Xiao, G. Yang, Y. Liu, S. Luo, W. Jie, J. Mater. Sci. Technol. 2246, 34 (2018) 